\title{
Tan cerca, tan lejos: Sagasta y los progresistas frente al republicanismo en el Sexenio Democrático*
}

\author{
José LUis OlLero Vallés \\ Instituto de Estudios Riojanos
}

(So close, so far: Sagasta and progresistas against
republicanism during Sexenio Democrático)

RESUMEN

El debate Monarquía-República alcanzó uno de sus momentos más álgidos con motivo del triunfo de la Revolución de Septiembre. No en vano, en la amplia coalición que se formase (progresistas, demócratas y unionistas) para destronar a la reina e inaugurar una nueva etapa de reformas políticas en sentido liberal pervivían concepciones muy diferentes respecto a la forma de gobierno que debía instalarse en el nuevo régimen salido de la revolución. El trabajo se interesa por el modelo monárquico defendido por los progresistas frente a las convicciones republicanas de los demócratas. El alejamiento entre ambas fuerzas y la particular dialéctica mantenida entre ellas durante el Sexenio quedan ejemplificadas a través de la actuación de Práxedes Mateo-Sagasta, figura clave de los primeros gabinetes y Presidente del Consejo con Amadeo, que llegó a encarnar el profundo desencuentro entre progresistas y republicanos.

\section{ABSTRACT}

The discussion about Monarchy vs. Republic reached one its most critical points due to the September Revolution success. In fact, in the wide coalition that was to be formed (progresistas, demócratas and unionistas) to dethrone the queen and open a new period of political reforms in the liberal sense, we can recognize different ideas about the most suitable government pattern that should be established in the new regime that came out of the revolution. Our paper deals with the monarchic project supported by progresistas against the republican convictions, characteristic of demócratas. The detachment between both political forces and their particular dialectics during the Sexenio Democrático are illustrated through Praxedes MateoSagasta's performance. This politician, who was the keystone of the first cabinets and Prime Minister with Amadeo de Saboya, reached the point of embodying the deep disagreement between both aforementioned groups.

\footnotetext{
" Este trabajo se enmarca en el proyecto de investigación Retórica e Historia. Los discursos parlamentarios de Práxedes Mateo-Sagasta, 1854-1874, radicado en la Universidad de La Rioja bajo la dirección del Dr. José Antonio Caballero López y perteneciente al Plan Nacional de Investigación Científica, Desarrollo e Innovación Tecnológica (Ref. BFF2002-00013).
} 
PALABRAS CLAVE:

Progresismo - Monarquía Constitucional República - Levantamientos republicanos federales - constitucionales - radicales Restauración borbónica - El Sol de la República - Práxedes Mateo-Sagasta.
KEYWORDS:

progresistas - Constitutional Monarchy -

Republic - federal republican uprising constitucionales - radicales - Borbonic Restauration - El Sol de la República Práxedes Mateo-Sagasta

«¡Viva la República! es frase que según el señor Sagasta no se puede decir» ${ }^{1}$.

El debate doctrinal acerca de la idoneidad de la forma de gobierno (monarquía o república) alcanzó particular intensidad a raíz del triunfo de la amplia coalición revolucionaria que ocupó el poder tras la Gloriosa septembrina. La alianza coyuntural que agrupó a fuerzas y sensibilidades políticas tan heterogéneas con el exclusivo horizonte del destronamiento de la reina Isabel II abrió, una vez materializado éste, tantas posibilidades como credos políticos integraban la entente revolucionaria. Demócratas y progresistas, desde el Pacto de Ostende, y buena parte de los unionistas, desde la primavera de 1868, habían llegado al convencimiento de la incapacidad de la reina para encabezar los destinos de la nación. Otra cosa bien distinta era decidir o consensuar cuál debía ser el camino a seguir y cuál la nueva formulación del ejecutivo a establecer. A este respecto, la pretendida cohesión revolucionaria pronto se reveló endeble al quedar enfrentada a la disyuntiva Monarquía-República. Fue precisamente en el seno del núcleo original de la alianza revolucionaria, el formado por progresistas y demócratas, donde la fractura pudo hacerse más visible. Las aspiraciones republicanas de buena parte de estos últimos no eran en modo alguno compartidas por los primeros, que ratificaban en toda circunstancia su «inquebrantable» monarquismo, al margen de su probada incompatibilidad con la versión isabelina, que había ido acrecentándose en el último tramo de su reinado.

Llegados a este punto, cabe preguntarse ¿cuál era exactamente la concepción que mantenían los progresistas acerca de la forma de gobierno? ¿en qué medida la incorporaron al diseño del nuevo régimen? ¿en qué términos se produjo el progresivo distanciamiento entre progresistas y republicanos en el desarrollo político del Sexenio? Para tratar de arrojar luz y sugerir algunas respuestas, proponemos fijar la mirada en la trayectoria de Práxedes Mateo-Sagasta, que no sólo resultó ser uno de los representantes más autorizados del progresismo puro isabelino sino que, además, actuó desde septiembre del 68 como un activo y comprometido gobernante, ocupando las carteras ministeriales de Gobernación y Estado hasta

\footnotetext{
${ }^{1}$ El Sol de la República, 11 de julio de 1869.
} 
Tan cerca, tan lejos: Sagasta y los progresistas frente al republicanismo en el Sexenio...

llegar a presidir el Consejo de Ministros en momentos clave de la consolidación y posterior derrumbamiento de la Monarquía demoliberal del Sexenio². Su fructífera aunque en gran medida inadvertida acción de gobierno y su particular enfrentamiento con los sectores republicanos a medida que se iba materializando el nuevo status político le llevaron a ocupar un lugar central en la dialéctica Monarquía-República que encontrase uno de sus mejores campos de pruebas en el cúmulo de experiencias desencadenadas entre 1868 y 1874.

\section{EL MODELO MONÁRQUICO DE LOS PROGRESISTAS}

Las convicciones monárquicas del liberalismo en cualquiera de sus versiones, moderada o progresista, permanecieron constantes a lo largo del prolongado periodo de consolidación del régimen liberal hispano. De hecho, la lealtad al trono había permitido aglutinar, en los momentos más críticos, las diferentes sensibilidades liberales al servicio de un proyecto común. Las diferencias programáticas de moderados y progresistas no afectaron nunca al modelo político de la monarquía constitucional, reclamado por ambos. Es cierto que en lo relativo al origen de la soberanía y los criterios de su legitimación, las discrepancias entre unos y otros fueron más que notables. Mientras los moderados tan sólo alcanzaban a bendecir una soberanía compartida entre las Cortes y la Corona, como trasunto de la pretendida síntesis entre los tiempos pasados y los nuevos, o sea, entre el absolutismo propio del Antiguo Régimen y el liberalismo revolucionario ${ }^{3}$, los progresistas apostaban, al menos en el plano del discurso teórico oficial, por la formulación de la soberanía nacional, que implicaba en última instancia el sometimiento del monarca a la voluntad del país en la determinación del rumbo político. Esta diferencia doctrinal estuvo siempre presente en el debate político hasta el punto de provocar célebres escándalos parlamentarios ${ }^{4}$. Sin embargo, mucho más allá de la con-

2 Sobre el progresismo isabelino deben consultarse los trabajos de ROMEO MATEO, M. ${ }^{\text {a }}$ C.: «Lenguaje y política del nuevo liberalismo: moderados y progresistas, 1834-1845", $A Y E R, \mathrm{n} .{ }^{\circ}$ 29, 1998, pp. 37-62, «La tradición progresista. Historia revolucionaria, historia nacional», en SUÁREZ CORTINA, M. (ed.): La redención del pueblo. La cultura progresista en la España liberal, Santander, Universidad de Cantabria / Sociedad Menéndez Pelayo, 2006, pp. 81-113, BuRDIEL, I.: «La tradición política progresista. Historia de un desencuentro», en DARDÉ, C. (dir.): Sagasta y el liberalismo español (Catálogo de la exposición), Madrid, Ministerio de Educación y Cultura / Ediciones del Umbral, 2000, pp. 103-121 y VILCHES GARCíA, J.: Progreso y libertad. El Partido Progresista en la Revolución Liberal española, Madrid, Alianza Editorial, 2001. Sobre Práxedes Mateo-Sagasta en su etapa progresista, disponemos de los recientes trabajos de DARDÉ, C.: «Sagasta o cómo sobrevivir en política», en MoRENo Luzón, J. (ed.): Progresistas, Madrid, ed. Taurus, 2005, pp. 91-115 y OlLeRo VAltés, J. L.: Sagasta. De conspirador a gobernante, Madrid, ed. Marcial Pons / Fundación Práxedes Mateo-Sagasta, 2006.

3 Una explicación de los presupuestos doctrinales de los moderados, en CAPELLÁn DE MıgueL, G., GóMEZ OCHOA, F.: El marqués de Orovio y el conservadurismo liberal español del siglo xix. Una biografía política, Logroño, Instituto de Estudios Riojanos, 2003, pp. 31-39; ver también SÁnchEz GaRcía, R.: «La Historia del siglo XIX desde la perspectiva moderada: reflexiones de Antonio Alcalá Galiano sobre España», Hispania, n. ${ }^{\circ} 204,2000$, pp. 289-314.

${ }_{4}$ Recuérdese la intervención del propio Sagasta en el debate sobre la unidad de Italia, en el que, al advertir que los derechos de los Borbones entraban en contradicción con las doctrinas que los progresistas pretendían para la Monarquía española al oponerse al dictado de la soberanía o «voluntad na- 
frontación «escénica» o de las presiones políticas a las que fue sometida por unos y otros la propia reina, la sucesión de cambios de gabinete, pronunciamientos y movimientos revolucionarios que jalonaron la etapa isabelina desde el final de la guerra civil carlista no alcanzaron al cuestionamiento de la corona hasta los primeros meses de 1866, momento en el que el espinazo central del progresismo, a instancias de un hastiado Prim, abandonó definitivamente toda esperanza de integrarse en el régimen como alternativa de gobierno.

Hasta entonces, las diferentes expresiones y enunciados políticos del progresismo isabelino habían situado explícitamente como pilar insustituible de la nueva planta liberal un «sistema monárquico constitucional amparado en la soberanía nacional ${ }^{5}$, que había sido el régimen político defendido por el primer liberalismo español desde los ensayos revolucionarios de 1812 y el Trienio Constitucional 6 . Dicho de otra manera, la forma monárquica era absolutamente consustancial al modelo del liberalismo progresista y la aceptación de la Corona, lejos de obedecer a cualquier tipo de oportunismo político, se basaba en una férrea confianza en su papel como garante de la consolidación del programa liberal. Es verdad que algún dirigente del primer progresismo, caso del alicantino Joaquín María López, trató de introducir en la esfera del liberalismo más avanzado conceptos y principios propios de la tradición republicana ${ }^{7}$. Pero el grueso de los dirigentes (Calatrava, Mendizábal, Olózaga, Vicente Sancho, Manuel Cortina, Pascual Madoz, Calvo Asensio, Joaquín Aguirre, y el propio Sagasta) y los diferentes Manifiestos y textos programáticos que fueron apareciendo desde la conformación del partido, a mediados de los años treinta, incluían invariablemente la alusión a la institución monárquica como garante de la mencionada voluntad nacional aunque se llegase a hablar de la idoneidad de «la monarquía templada, o sea mixta, que es la primitiva española, conocida hoy por monarquía constitucional»; una síntesis de «lo bueno de la monarquía y lo mejor de las repúblicas ${ }^{8}$. Lo que los progresistas isabelinos veían aprovechable de la fórmula republicana, aunque lo quisieran integrar siempre en moldes monárquicos, era la preocupación por el interés público y la concepción de la ley como fruto de la voluntad de la nación. De todas maneras, aunque el dis-

cional», llegó a afirmar que la Reina lo era precisamente «por este principio, nada más que por este principio", Diario de Sesiones de las Cortes (DSC), Congreso, Legislatura de 1860, sesión del 6 de marzo de 1861, p. 1856.

5 Tomado del Manifiesto-programa dirigido a los electores de la provincia de Zamora (12 de septiembre de 1854) [por el candidato Práxedes Mateo Sagasta], Zamora, Imprenta de B. Velasco, 1854, reproducido en El Heraldo de Zamora, 9 de enero de 1903.

${ }^{6}$ Aunque la formulación gaditana, más avanzada, respondiese en puridad a lo que se ha categorizado como «Monarquía Parlamentaria», ver ARTOLA, M.: "La Monarquía Parlamentaria», AYER, n. ${ }^{\circ}$, 1991, pp. 105-123.

7 A este respecto, consultar el valioso trabajo de Romeo MATEO, M. ${ }^{a}$ C.: «Joaquín María López, un tribuno republicano en el liberalismo", en MORENO Luzón, J. (ed.): Progresistas. Biografías de reformistas españoles (1808-1939), Madrid, ed. Taurus, 2006, pp. 59-98.

8 «Breve contestación al difuso escrito del señor Don Nicomedes Pastor Díaz, con motivo de las elecciones», Archivo Histórico Municipal de Valencia, Hojas políticas, 1839, cit. en ROMEO MATEO, M. ${ }^{a}$ C.: «Las utopías liberales, una herencia en discusión», Berceo, n. ${ }^{\circ}$ 139, 2000, p. 21. 
curso oficial subrayase que la institución monárquica debía respetar y avalar el veredicto emitido por la opinión del país (a través de las convocatorias electorales), el progresismo, de facto, acabó aceptando su función arbitral y reguladora de la vida política.

Lo que nunca terminó de asimilar fue su paulatino alejamiento del poder «sancionado" por la reina tras determinadas coyunturas (1840-43 o 1854-56) que comportaron algunas experiencias traumáticas para la propia familia real ${ }^{9} \mathrm{y}$ derivaron en la paulatina negación de confianza política a los progresistas. El exclusivismo moderado arbitrado por la corona acabó generando un problema de gobierno ya que se hizo imposible una dinámica cuando menos bipartidista, lo que acarreó la marginación de las fuerzas de oposición, especialmente la del partido progresista, que era la alternativa natural al moderantismo. Sólo en esta dinámica y a causa de lo que ellos mismos denominaron «obstáculos tradicionales» que les apartaban del poder, el partido adoptó el camino del retraimiento electoral, primero, y se lanzó abiertamente, después, a la revolución antidinástica ${ }^{10}$. De esta manera, la fe monárquica de los progresistas acabó derivando en una certeza anti-isabelina que les condujo a la Revolución de septiembre.

\section{LA DECANTACIÓN MONÁRQUICA DEL NUEVO RÉGIMEN Y LOS EFECTOS NO DESEADOS}

A diferencia de lo sucedido en la anterior revolución triunfante, la de julio de 1854, que vivió en pocas semanas la jornada de la inauguración de las Cortes Constituyentes con un multitudinario desfile por las calles de Madrid en el que la reina salió del Palacio Real, recorrió la calle Mayor, la Puerta del Sol y alcanzó, entre aclamaciones y gritos frenéticos de ;Viva la Reina!, la Carrera de San Jerónimo y el Palacio del Congreso, los desfiles que siguieron al triunfo de la Gloriosa fueron de signo muy diferente. Esta vez, los vivas, los parabienes y las aclamaciones callejeras que volvieron a inundar las calles de la capital no iban dirigidas a la reina, que había abandonado días atrás su retiro estival en la costa cantábrica y había atravesado por Irún la frontera, camino de París, en la más absoluta soledad. Eran buena parte de los principales generales y líderes civiles de las fuerzas pronunciadas los que ocupaban ahora los lugares de honor en la comitiva que salió desde la fuente de Neptuno para alcanzar el edificio del Congreso, cuyo vestíbulo

9 Episodios tan recordados como el forcejeo de la reina niña con Olózaga (fuese o no exageradamente malinterpretado) o escenas vividas en Palacio menos conocidas pero igual de poco edificantes, como la que sitúa a la joven Isabel, presa del pánico, llorando, «a punto de un ataque de nervios», ante ciertas maniobras esparteristas en las jornadas de julio de 1854, permanecieron siempre en el inconsciente de la reina y su entorno más próximo, ver BURDIEL, I.: Isabel II. No se puede reinar inocentemente, Madrid, ed. Espasa-Calpe, 2004.

10 Ver Ollero Vallés, J. L.: «Sagasta y el progresismo frente a los obstáculos tradicionales», Berceo, n. ${ }^{\circ} 139,2000$, pp. 32-51. 
aparecía profusamente adornado con arcos de musgo, flores, banderas y escudos con el lema ;Viva la soberanía nacional!'11.

A la parafernalia del acto festivo, que permitió ver juntos a Pascual Madoz, Ros de Olano, Nicolás Rivero o Francisco García López y tuvo continuidad, días después, con el entusiasta recibimiento a los protagonistas del movimiento iniciado en la bahía de Cádiz, como los generales Serrano, López Domínguez y el propio Sagasta, le siguió en los días posteriores la necesaria reestructuración del nuevo edificio institucional. De acuerdo con la tradición revolucionaria ya secular, la formación en toda la península de Juntas locales y provinciales fue otra vez el mecanismo utilizado para la conformación de una nueva legitimidad política. La composición de las Juntas dejaba ya traslucir determinadas tendencias que matizaban la amplia y heterogénea coalición formada por las elites revolucionarias. El mejor entendimiento entre progresistas y demócratas hizo que los unionistas fuesen minoritarios o, incluso, quedasen excluidos de algunas de ellas ${ }^{12}$. De hecho, en la capital figuras relevantes de las dos primeras fuerzas, como Pascual Madoz, José Olózaga, Laureano Figuerola, Nicolás Rivero, Bernardo García o Eduardo Chao decretaban la abolición de la dinastía y se constituían en el Ayuntamiento como Junta interina. Ese mismo día, se convocaban elecciones por sufragio universal en los diferentes distritos para la configuración de la Junta definitiva. La intención que latía en la medida apuntaba a una ratificación de las elites de gobierno mediante un procedimiento democrático formal tras la legitimación popular que se había vivido en las calles días atrás. Las candidaturas de coalición, en las que estaban incluidos ya los dirigentes que, procedentes de la emigración, no habían llegado todavía a la capital, dieron cabida preferente a los monárquicos de todo signo frente a los republicanos. Así, por el distrito del Centro fueron elegidos Ruiz Zorrilla, Manuel Cantero y Manuel Becerra; por el de Palacio, Serrano, Joaquín Aguirre y Nicolás Rivero; y en Hospicio, Práxedes Mateo-Sagasta ${ }^{13}$.

Fue a partir de este momento cuando se trabajó con la idea prioritaria de definir la naturaleza del nuevo régimen, tarea que venía condicionada por los acuerdos previos alcanzados en la bahía gaditana entre los caudillos unionistas y progresistas, de inequívoca adscripción monárquica. Tal y como relataba años después Ricardo Muñiz recreando las precisas instrucciones que había recibido de Prim en Cartagena, se trataba de «recibir con grande ostentación y entusiasmo al duque de la Torre

\footnotetext{
11 Las impresiones sobre la jornada de inauguración de las Constituyentes de 1854, tal y como lo transmitía el nuncio Franchi al cardenal Secretario de Estado en carta del 13 de noviembre, en NúÑEZ MuÑOZ, M. ${ }^{a}$ F., DíAZ DE CERIO, F.: El Bienio Progresista (1854-1856) y la ruptura de relaciones de Roma con España según los documentos vaticanos, Secretariado de Publicaciones de la Universidad de La Laguna, 1993, p. 59; la descripción pormenorizada del desfile de octubre de 1868, en LARA, M. M. de: El cronista de la Revolución española de 1868. Narración fiel de todos los sucesos, con todos los documentos oficiales que se han publicado durante su curso hasta la constitución del gobierno provisional, Barcelona, Imprenta de Celestino Verdaguer, 1869, pp. 168-171.

12 De la Fuente Monge, G.: Los revolucionarios de 1868. Elites y poder en la España liberal, Madrid, ed. Marcial Pons, 2000, p. 119.

13 La Iberia, 3 y 4 de octubre de 1868.
} 
y sus heroicos soldados, [y] facilitarle que inmediatamente formara Gobierno, pues de ese modo cesarían las Juntas, que ya para nada eran necesarias ${ }^{14}$. De acuerdo con estos planes y con la combinación de fuerzas previsible, la Junta de Madoz reconocía a Serrano como general en jefe del Ejército español y resignaba el poder a la nueva «Junta superior revolucionaria» en la noche del 5 de octubre. En ella figuraban como presidentes honorarios Serrano y Prim, como presidente efectivo, el anunciado Joaquín Aguirre, y como vicepresidentes Rivero y el marqués de la Vega de Armijo. Como era de suponer, Sagasta también formaba parte de la misma.

La recién estrenada Junta, ya con la presencia de Prim, optaba por dirigirse al país para reafirmar sus convicciones y anticipar sus intenciones futuras en relación con el traspaso del poder a los órganos competentes. En su Manifiesto del 7 de octubre se hacían ya las primeras alusiones al «Gobierno provisional que está para formarse" y se expresaba la confianza de que la obra de la revolución iniciada por «eminentes patricios» llegara a «verse coronada por las Cortes Constituyentes» ${ }^{15}$. La elección de los hombres apropiados respondía, básicamente, a lo pactado con Prim ${ }^{16}$, por lo que se imponía un consenso monárquico con presencia dominante de progresistas y unionistas bajo la jefatura de Serrano, designado por los cabecillas desde el pronunciamiento gaditano. Aunque algunas Juntas expresaron su disconformidad con el procedimiento seguido, al no contar con su concurso, y propusieron la formación de una Junta Central mediante el consabido procedimiento centrípeto a partir de las designaciones provinciales, Serrano hizo rápidamente pública la composición del Gobierno Provisional, desactivando cualquier interferencia en ese sentido. La rapidez para su proclamación atendió además a la inquietante percepción que acompañó a Prim durante su periplo mediterráneo antes de recalar en la capital al advertir la importancia de las movilizaciones republicanas y sus tendencias federalizantes. Aunque en ese gabinete se le había ofrecido una cartera, la de Gracia y Justicia, a Nicolás Rivero, las mayores exigencias de los demócratas, obviamente insatisfechas, acabaron determinando su no participación en el nuevo gobierno.

La celeridad y el sesgo imprimido a las grandes decisiones políticas no fueron bien recibidas por las Juntas provinciales, que empezaron a manifestar serias reticencias a las actuaciones del Gobierno en la capital. Algunas de ellas no se creían obligadas a acatar la formación del nuevo gobierno por creerlo «puramente de la provincia de Madrid» ${ }^{17}$. Sin embargo, la maniobra gubernamental que despertó mayores recelos y originó una fuerte crispación fue la publicación del Mani-

14 MuÑIz, R.: Apuntes históricos sobre la revolución de 1868, Madrid, 1885, tomo I, pp. 244-245.

15 Manifiesto de la Junta Superior Revolucionaria de Madrid (Madrid, 7 de octubre de 1868), Hemeroteca Municipal de Madrid, A/1348.

16 Respecto al «doble juego» de Prim con los republicanos y con los grupos más conservadores del movimiento revolucionario, y sus incumplimientos respecto a los primeros, véase ANGUERA, P.: «Prim (18141870): de miliciano a Presidente del Gobierno", en SERRANo GarcíA, R. (coord.): Figuras de la Gloriosa. Aproximación biográfica al Sexenio Democrático, Valladolid, Universidad de Valladolid, 2006, pp. 15-30.

17 Monlleó Peris, R.: La Gloriosa en Valencia (1864-1869), Valencia, Generalitat Valenciana / ed. Alfons el Magnànim, 1996, p. 45. De hecho, la Junta valenciana ralentizó todo lo que pudo el cese de fun- 
fiesto del 25 de octubre, en el que el Gobierno se decantaba, aunque nunca de forma explícita, por la opción monárquica ${ }^{18}$. Al día siguiente, la multitudinaria reunión de la Tertulia Progresista venía a confirmar dicha línea política. Presidida por Salustiano de Olózaga, que expuso la conveniencia de una «monarquía liberal», allí se pactó la unidad de acción ente los hombres del progresismo y la Unión Liberal. El general Blas Pierrad, que asistió al acto acompañado de Francisco Córdova, «viéndose engañado, protestó enérgicamente en nombre del partido republicano federal español y de sus trabajos y sacrificios por la revolución septembrina ${ }^{19}$. El sueño de la coalición revolucionaria empezaba a desvanecerse a los pocos meses de su apogeo. Aparecían los primeros efectos no deseados de la necesaria decantación política del nuevo régimen.

\section{LA FRACTURA ENTRE PROGRESISTAS Y REPUBLICANOS. SAGASTA AL SOL DE LA REPÚBLICA}

Por su parte, Sagasta, elegido por Serrano y Prim para ostentar la decisiva cartera de Gobernación, se aplicaba a poner en pie todo un entramado legal de nuevo cuño (Decreto de la nueva Ley Municipal, Decreto que reglamentaba la actuación de los Voluntarios de la Libertad, Decreto de aprobación de la libertad de asociación...) que acarreaba una nueva organización de la administración territorial sobre la que sustentar la acción de gobierno ${ }^{20}$. Se trataba, en todo caso, de una estructuración «desde arriba» que neutralizaba el modelo alternativo "desde abajo» de raíz federal ${ }^{21}$. A todo ello se le unió la destacable aprobación, por vez primera en la historia de España, de una nueva Ley Electoral que incorporaba el sufragio universal (masculino) directo. Semejante incorporación, debida antes a la presión ejercida por demócratas y republicanos que a las verdaderas convicciones de los círculos progresistas en los que se movía el ministro ${ }^{22}$, certificaba un más

ciones antes de adherirse a lo solicitado por el Gobierno Provisional, Martínez Andreu, F. A.: Prensa y partido en el progresismo valenciano. José Peris y Valero (1821-1876), Valencia, Biblioteca de L'Ateneu de Periodistes, 1994, p. 208; otras, como la de Barcelona, mostraron abiertamente su descontento, JANUÉ I MiRET, M.: La Junta revolucionaria de Barcelona de l'any 1868, Vic, ed. Eumo, 1992, p. 27 y ss., aunque la más contundente resultó ser la de Teruel, VillanUEVA HERRERO, J. R.: El republicanismo turolense durante el siglo XIX (1840-1898), Zaragoza, ed. Mira, 1993, p. 114 y ss.

18 «España podrá proceder tranquilamente al establecimiento definitivo de la forma de gobierno que más en armonía esté con sus condiciones esenciales y sus necesidades ciertas, que menos desconfianza despierte en Europa [...] y que mejor satisfaga las exigencias de su raza y de su costumbre», BOZAL, V.: Juntas Revolucionarias. Manifiestos y proclamas de 1868, Madrid, Edicusa, 1968, p. 116.

19 Según su acompañante, "pidió cinco veces la palabra [...] y ninguna de ellas le fue concedida», CóRDOVA LóPEZ, F.: El proceso del partido progresista y la soberanía nacional, Madrid, 1871, pp. 34-37.

20 Todos los Decretos, en El Ministerio de la Gobernación durante la Revolución de 1868, Madrid, Ministerio del Interior, 1990.

21 Sobre esta cuestión, ver VILLENA ESPINOSA, R.: «La crisis del Estado centralista y la administración territorial en el Sexenio», $A Y E R$, n. ${ }^{\circ} 44,2001$, pp. 83-107.

22 Sobre las posiciones progresistas acerca del sufragio universal, ver OLLERO VALLÉs, J. L.: «De la liberación del preso encadenado al salto en las tinieblas: sobre representación y autenticidad en la cultura política del progresismo», AYER, n. ${ }^{\circ} 61,2006$, pp. 105-137. 
que evidente esfuerzo reformista y la materialización de viejas aspiraciones de los sectores más avanzados del liberalismo y del propio republicanismo.

En todo caso, los sectores más vinculados a este último no terminaron de aceptar lo que se les ofrecía. Pudiera parecer un contrasentido o una paradoja pero fue precisamente en aquel escenario político en el que podían encontrarse más concordantes los intereses del liberalismo progresista y del republicanismo, haciendo abstracción siempre del insuperable escollo de la definición del ejecutivo, cuando se inició una línea de fractura que fue agravándose con pasmosa rapidez. Así, el Comité electoral del Partido Demócrata Republicano de Madrid, formado tras las votaciones de los días 8,9 y 10 de noviembre, proclamaba sin rubor la incompatibilidad de la monarquía con las nuevas libertades conquistadas por la Revolución ${ }^{23}$. El desbordamiento por la izquierda de la hasta entonces relativamente disciplinada conjunción de fuerzas revolucionarias empezó a precipitarse hacia la sucesión lógica que proponía en su primera cabecera el periódico bisemanal El Sol de la República, que comenzasen a editar los republicanos logroñeses: «La libertad está sólo en la Democracia, la Democracia está sólo en la República, la República es sólo verdad en la Federación»²4.

El ministro ya se hacía eco a finales de noviembre de las noticias que le llegaban acerca de «la perturbación de reuniones pacíficas [...] de ciudadanos honrados y partidarios de la forma monárquica» y «la proclamación de principios absurdos [...] y amenazas más o menos encubiertas de cohibir por la fuerza la libertad del sufragio". En vista de ello, Sagasta daba instrucciones precisas a los Gobernadores para que interviniesen, "por sí o por medio de sus delegados» para «impedir que minorías o parcialidades turbulentas se opongan a la manifestación tranquila de todas las opiniones o hagan imposible, como ya por desgracia ha sucedido en algún punto, la discusión ordenada que intente una mayoría respetable ${ }^{25}$. Así las cosas, la desconfianza entre monárquicos y republicanos que había ido larvándose en las semanas previas cristalizaba finalmente a finales de año en las vísperas de la primera consulta electoral. El propio Sagasta experimentó en su propia piel aquella divergencia súbita que pronto se hizo insalvable. Tras llegar a formar parte de una candidatura conjunta de progresistas y republicanos en Logroño, fue retirado de la misma y reemplazado por un conocido republicano local, Timoteo Alfaro, imponiéndose así la lógica bipolar que acabaría impregnando la convocatoria electoral ${ }^{26}$. Además, los republicanos buscaban hurgar en las frac-

23 Ver PéRez Roldán, C.: El Partido Republicano Federal, 1868-1874, Madrid, ed. Endymion, 2001, p. 54 y Esteban Navarro, M. A.: «De la esperanza a la frustración, 1868-1873», en Townson, N.: El republicanismo en España (1830-1977), Madrid, Alianza Editorial, 1994, pp. 87-113.

24 El Sol de la República, n. ${ }^{\circ}$, 17 de diciembre de 1868, p. 1. El largo editorial que justificaba el lanzamiento del periódico iba precedido de un esclarecedor título (en todos los sentidos): «El Sol de la República, iluminando y dando vida al mundo liberal».

${ }_{25}$ Circular del Ministro a los Gobernadores civiles de 29 de noviembre de 1868, en El Ministerio de la Gobernación..., op. cit., pp. 150-151.

${ }_{26}$ Compartía candidatura con el general Espartero y los republicanos Alberto Ruiz Royo y Pablo Alemán. Sin embargo, a instancias de cierto afiliado republicano local y según «recomendación de nuestro 
turas y rivalidades internas del progresismo tratando de ganar para su causa a los desengañados seguidores de Espartero, único progresista al que se mantuvo, y no sólo en Logroño, en candidaturas de inspiración republicana:

«Progresistas, los que lleváis en el corazón el deseo del bien patrio, [...] el gobierno provisional os prepara un soberano extranjero para consumar bajo su amparo la execrable obra de la reacción.

Progresistas, amantes de Espartero, abandonad a los monárquicos quienes no le aceptan; abandonad la candidatura en que se coloca junto a Olózaga, su capital enemigo, como para escarnecerle; abandonad a los que no cumplen la inscripción de la bandera de Cádiz, [...] ensayad con nosotros la república, único gobierno verdadero, ensayadla bajo los auspicios de ese respetable varón ${ }^{27}$.

Uno de los monárquicos «execrables» era, sin duda, Sagasta, que, por su parte, se sacudía el «acoso» de los republicanos minimizando su participación en los preparativos revolucionarios al tildarles de «cobardes» y preguntarles «dónde estaban antes de septiembre» ${ }^{28}$. Además, ya en su calidad de ministro, Sagasta se veía obligado a variar los planes previstos. Las revueltas que se registraron con especial virulencia en Andalucía le habían llevado a aplazar las elecciones municipales previstas para el 1 de diciembre. Además, el decreto de convocatoria de las elecciones a diputados, que disponía la celebración de los comicios para los días 15 al 18 de enero, hacía advertencias muy explícitas:

«El gobierno será neutral, pero no escéptico; hará que sean profundamente respetadas y libérrimamente expresadas todas las opiniones»29.

El ambiente enrarecido en el que se desarrollaron las elecciones municipales, con nuevas alteraciones del orden público neutralizadas por las autoridades provinciales llevaron a Sagasta a enviar una nueva circular a los gobernadores civiles días antes de las elecciones a Cortes. En ella, el ministro denunciaba abiertamente

amigo y correligionario D. Roque Barcia», fue retirado de la lista y sustituido por el «consecuente liberal y republicano ciudadano D. Timoteo Alfaro a completa satisfacción de todos», El Sol de la República, 27 de diciembre de 1868 .

27 «Manifiesto a los electores de la provincia de Logroño», El Sol de la República, 3 de enero de 1869. Los diferentes gestos de acercamiento y las sucesivas iniciativas para atraerse al duque y postularle como futuro «rey de España» por parte de los republicanos [¿?] logroñeses, en SicILIA ARENZANA, F.: Un monarca... y la República, o Espartero, rey. Consejos sanos de actualidad, Logroño, Imprenta y Litografía de F. Menchaca, 1868, pp. 9-12. El texto completo del Manifiesto, recogido en SÁEz MIGUEL, P.: El Sexenio Democrático en Logroño. Comportamientos colectivos y protagonismos políticos, 18681874, (Tesina de Licenciatura), Universidad de La Rioja, 2001, pp. 188-190. Los antecedentes del republicanismo riojano, en SÁEZ MIGUEL, P.: «El republicanismo en La Rioja (1849-1903)», en SÁNCHEZ Collantes, S., Cabrero Blanco, C., Fernández Bas, X., Rodríguez Infiesta, V. (coords.): El republicanismo en España: política, sociedad y cultura (Comunicación presentada al Congreso celebrado en Oviedo, 2004), y «Política y políticos en La Rioja: sexenio democrático (1868-1874)», Brocar, n. ${ }^{\circ} 26,2002$, pp. 229-243.

28 El Sol de la República, 14 de enero de 1869.

29 Decreto de 6 de diciembre de 1868, cit. en Monlleó PeRIS, R.: «Republicanos contra monárquicos. Del enfrentamiento electoral y parlamentario a la insurrección federal de 1869 ", AYER, n. ${ }^{\circ} 44,2001$, p. 59. 
los graves sucesos de algunas ciudades, «las sublevaciones del Puerto de Santa María y Cádiz, y la reciente de Málaga, criminales e injustificadas [...], las conspiraciones descubiertas en Pamplona, Burgos y Barcelona», y apuntaba a su verdadero propósito: «impedir a todo trance la reunión de las Cortes».

Parece pertinente resaltar aquí que la comunicación del ministro adquiría, por primera vez, ciertos tintes dramáticos:

«El Gobierno conoce hace tiempo los planes de los que quieren matar la libertad presentándola como imposible por medio de continuas perturbaciones [...] e imponer a la parte del pueblo verdaderamente liberal un retraimiento forzado, al amparo del cual se proponen los agitadores no encubiertos convertir en mayorías hasta las minorías más insignificantes»,

\section{que le llevaban a transmitir que el Gobierno}

«se halla tan dispuesto a proteger la fuerza ciudadana allí donde sea un elemento de orden y baluarte de la libertad, como a impedir que los perturbadores de oficio o los agentes de la reacción consigan convertirla en instrumento de anarquía. Que el Gobierno [...] será inexorable en el cumplimiento de los decretos publicados y salvará con la misma energía que en Málaga y Cádiz la causa de la sociedad, haciendo respetar la propiedad y asegurando el sosiego público»30.

De todas maneras, el tono de firmeza empleado no conseguiría disuadir las irrefrenables pulsiones sociales desencadenadas. Coincidiendo con las jornadas electorales, se consumaron nuevos levantamientos en Granada, Sevilla, Loja y Jerez a los gritos de «iViva la República y mueran los ricos!». Las manifestaciones de una incipiente conmoción social llegaron a también a amplias zonas del país, como Galicia, Asturias, Castilla, Extremadura, Cataluña o el País Valenciano. En todos estos lugares, las extremas condiciones laborales y los problemas de escasez hicieron anidar un profundo malestar, con episodios de protesta de variado sig$n^{31}$. La magnitud de los acontecimientos llevó a Sagasta a dirigir a los republicanos en las Cortes durísimas acusaciones en las que les reprochaba «hayan ofrecido repartir tierras que no eran suyas", lo que mereció inmediatas reacciones en la prensa republicana, algunas plenas de ingenio:

«... Que repartimos las tierras

dijo en las Cortes Sagasta

${ }^{30}$ Circular a los Gobernadores Civiles de 5 de enero de 1869, El Ministerio de la Gobernación..., op. cit., pp. 179-181.

${ }_{31}$ Algunos de estos episodios pueden seguirse en GIL Novales, A.: La Revolución de 1868 en el Alto Aragón, Zaragoza, ed. Guara, 1980, pp. 95-99, SerRAno García, R.: El Sexenio Revolucionario en Valladolid. Cuestiones sociales (1868-1874), Valladolid, Junta de Castilla y León, 1986, p. 50 y ss., CARO CANCELA, D.: Burguesía y jornaleros. Jerez de la Frontera en el Sexenio Democrático (1868-1874), Jerez, Caja de Ahorros de Jerez, 1990, o SÁnchez MARRoYo, F.: Movimientos populares y reforma agraria. Tensiones sociales en el campo extremeño durante el Sexenio Democrático (1868-1873), Badajoz, Diputación de Badajoz, 1992, p. 52 y ss. 
Él sí que es el que reparte

el presupuesto a su casta»32.

No debe extrañar, pues, que el Gobierno tomase mayores precauciones y se aplicase más de cerca en esta nueva consulta electoral. En esas condiciones, las primeras elecciones por sufragio universal directo en la historia española se caracterizaron por una movilización política desconocida hasta entonces aunque acabase condicionada por una marcada bipolaridad entre opciones monárquicas y republicanas. Lógicamente, la falta de costumbre y lo incipiente de la cultura y usos democráticos explicaba ciertas inercias y comportamientos electorales tradicionalmente admitidos ${ }^{33}$. Así que las buenas intenciones expresadas por el ministro no hicieron desaparecer las protestas y denuncias ante determinados amaños electorales. Tampoco resultó ninguna novedad que el Gobierno convocante obtuviera una amplia mayoría de representantes. La composición de las nuevas Cortes arrojaba una presencia hegemónica de los monárquicos, si bien las candidaturas republicanas encontraron amplio apoyo en una veintena de ciudades de Andalucía, Galicia, Cataluña y País Valenciano. Desde las primeras sesiones de las Constituyentes, pudo percibirse con nitidez que la fractura entre monárquicos y republicanos iba a guiar los debates sobre las principales cuestiones. Por eso, se ensayaron algunos gestos para tratar de frenar estas grietas. Así, a pesar de que desde amplios sectores del progresismo se postuló la candidatura de Olózaga para la Presidencia de la Cámara, un postrero gesto de acercamiento a los republicanos favoreció la designación del demócrata Nicolás Rivero para tal responsabilidad.

De todas maneras, las heridas seguían abiertas. La primera intervención del ministro Sagasta ante la nueva cámara fue dedicada a la defensa de la actuación del ministerio ante las imputaciones de Emilio Castelar en las que acusaba al Gobierno Provisional de «haber faltado a sus deberes, declarándose partidario de la Monarquía» y «haber violado los derechos individuales [...] y entorpecido con sus actos la marcha de la revolución». Desde la honda preocupación, Sagasta recordaba al incisivo interpelante los compromisos acordados en la jornada de la bahía de Cádiz y justificaba la declaración monárquica, «la hizo el Gobierno cuando vio que con el silencio monárquico no se oía más ruido que el de los republicanos y cuando de fuera nos preguntaban: ¿es que en ese país se han acabado los monárquicos y se va a establecer la república? ${ }^{34}$.

Las explicaciones del ministro no convencían en los bancos de los diputados republicanos, que comenzaban a denunciar ciertas contradicciones que asomaban en

32 El Sol de la República, 7 de marzo de 1869.

33 Entre ellos, el apoyo preferente a los candidatos, a título personal, más allá del partido en el que se encuadraban o la elección de algunos políticos por varias circunscripciones a pesar de su anunciada opción por alguno de ellos o incluso su total pasividad y renuncia al escaño, ver DE LA FUENTE MONGE, G.: «Elite política y clientelismo durante el Sexenio Democrático (1868-1874)», en RoBLES EGEA, A. (comp.): Política en penumbra. Patronazgo y clientelismo políticos en la España contemporánea, Madrid, ed. Siglo XXI, 1996, p. 156.

34 DSC, Congreso, Cortes Constituyentes de 1869, sesión del 24 de febrero de 1869, p. 186. 
la actuación del antiguo conspirador y agitador del progresismo. El diputado Joarizti, al recriminarle su procesamiento por la autoría de un artículo aparecido en el diario La lgualdad en el que se llamaba a la «protesta unánime contra el inicuo proceder del Gobierno", se sorprendía de que «el señor Sagasta, el antiguo periodista, el antiguo director del periódico progresista La lberia se levante a hacernos cargos semejantes". Tampoco fueron celebradas las argumentaciones ofrecidas por el ministro para justificar la postergación del decreto de amnistía por el que clamaban los republicanos. Sagasta, tras reconocer que dicho decreto llevaba algún tiempo preparado, aseguraba que no se llegaría a publicar hasta que no fuese neutralizada una «vasta conspiración» de variada procedencia a la que concedía tintes alarmantes puesto que no sólo «los carlistas siguen alistándose y armándose y prepararse para echarse al campo», sino que «la reacción [...] se cala el gorro frigio y procura envolvernos en la anarquía con los siniestros amagos de la guerra civil»35.

Tras la aprobación del nuevo texto constitucional, rechazado por los republicanos en virtud del establecimiento de la forma monárquica del Estado, el nuevo ministerio formado por Prim en junio no supuso cambio alguno en la composición de fuerzas políticas. Sagasta conservaba la cartera de Gobernación en plena campaña para el mantenimiento del orden y el acatamiento de la Constitución. Por su parte, el ministro de Gracia y Justicia, Cristóbal Martín Herrera, publicaba una circular en la que pretendía cerrar el debate que todavía seguía abierto en torno a la forma de gobierno. En ella se subrayaba que era la Monarquía la forma que había sido establecida por la Constitución y, en consecuencia, era por la que debía regirse la nación española. Quedaban, por ello,

«proscritas todas las aspiraciones inconciliables con la solución adoptada [...] y cualquier acto contrario a ella, sea en sentido republicano, sea en el absolutista o falsamente llamado legitimista [...] deb[ía] ser reprimido sin debilidad ni contemplaciones» ${ }^{36}$.

Por su parte, Sagasta justificaba en el Parlamento las instrucciones y órdenes trasladadas a los Gobernadores, arremetiendo con la consabida energía contra los diputados republicanos y su connivencia con las alteraciones urbanas:

«[...] en el mismo día en que se promulgaba la Constitución, se reúnen los republicanos federales y recorren las calles con banderas y enseñas a los gritos de ¡viva la república federal! [...] y dando mueras a las Cortes Constituyentes, a la Constitución y a los monárquicos [...] esos republicanos apedrean las casas de los ciudadanos que las han iluminado y atacan a pedradas la casa de uno de nuestros compañeros [...]

¿Es así como debe entenderse la libertad? ¿es así como se entiende el ejercicio de los derechos individuales?» ${ }^{37}$,

35 DSC, Congreso, Cortes Constituyentes de 1869, sesión del 4 de marzo de 1869, p. 303.

36 Circular del Ministro de Gracia y Justicia de 22 de junio de 1869, Archivo Histórico Nacional (AHN), Fondos Contemporáneos, serie A, legajo 44/2, expediente n. ${ }^{\circ} 17$.

37 DSC, Congreso, Cortes Constituyentes de 1869, sesión del 25 de junio de 1869, pp. 3070-3071. 
El abismo que separaba ya entonces a los progresistas y a los republicanos, antaño compañeros de viaje, adquirió un irreparable dramatismo con motivo del fatal desenlace de una concentración republicana en Tarragona, que encontró un inesperado final: el asesinato del gobernador civil interino de la provincia, Raimundo García Reyes, que se había presentado ante los responsables de la convocatoria para advertirles de la ilegalidad de ciertas exaltaciones callejeras. A pesar de que los republicanos tarraconenses condenaron inmediatamente el crimen, las acusaciones más o menos veladas arreciaron desde la prensa monárquica. Sagasta reaccionó con prontitud y dictó una nueva circular dirigida a los gobernadores dando instrucciones expresas para atajar los excesos observados en el ejercicio de los derechos de reunión y asociación. En dicha circular se conminaba, de un lado, a

«intimar a todas las asociaciones [...] cuyos asociados no h[ubier]an puesto en conocimiento de la autoridad local su objeto y los reglamentos y acuerdos por que aquéllas $\mathrm{h}[\mathrm{ubier}] \mathrm{an}$ de regirse, [...] a que suspend[iesen] inmediatamente sus sesiones hasta llenar estos requisitos».

Además, se ordenaba no sólo

«reprimir con mano fuerte y por todos los medios que las leyes ponen a su alcance los excesos y atentados que se cometan, aun en aquellas asociaciones constituidas con las condiciones legales, no tolerando en ellas ni gritos subversivos, ni ataques a la Constitución monárquica de la Nación, ni amenazas a la propiedad, a la honra o a la vida de los ciudadanos»

sino también, «con igual energía»,

los que se cometan en las reuniones o manifestaciones, declamando o protestando tumultuariamente contra la organización monárquica [...] o proclamando por medios de vivas, motes o banderas principios contrarios a los que la ley fundamental del Estado tiene consignados» ${ }^{38}$.

El enrarecido clima político que se instaló en el debate público a partir de entonces quedaba perfectamente ejemplificado con el tratamiento que recibió Sagasta en el órgano de prensa de los republicanos logroñeses. Al entonces ministro se le comparaba con González Bravo, «reaccionario era éste y reaccionario es Sagasta hasta el punto de confundirse uno con el otro" y se le llegó a calificar como "Calomarde II», lo que condujo a un proceso judicial por delito de desacato que llevó al juez a dictar auto de prisión para el redactor Víctor Padilla aunque posteriormente fuese indultado. Los colaboradores habituales del periódico, lejos de amedrentarse, no dudaron en referirse al otrora respetado paisano como

«ministro altivo, despótico y procaz, ese revolucionario de pega, ese ambicioso vulgar que [...] ha insultado y provocado al pueblo español con circulares dictato-

38 Circular a los gobernadores civiles de 25 de septiembre de 1869, AHN, Fondos Contemporáneos, serie A, legajo 44/2, expediente n. ${ }^{\circ} 17$. 
riales y despóticas, ha desarmado las Milicias ciudadanas y, con tantas ilegalidades y provocaciones, ha sido el autor principal de los tristes acontecimientos que han ensangrentado el suelo de la patria» ${ }^{39}$.

Aún más, a lo largo de los primeros semanas de 1870, se instaló en las páginas del diario republicano una auténtica fijación persecutoria contra el entonces ministro de Estado, al que se le achacaban todas las desgracias y todos los males del periplo revolucionario. No solamente se hacía hincapié en su utilización habitual «de la difamación y la calumnia para combatir a los republicanos» e «injuriar a los federales logroñeses» sino que se le adjudicaban «aviesas intenciones» concretadas en su acercamiento a los unionistas y hasta su defensa de la candidatura de Montpensier al trono español. Tan es así que como Sagasta se refiriese a la «sagastitis» que había anidado en aquella redacción, le llegaron a dedicar una corrosiva coplilla con idéntico título en la que le afeaban «la ambición de poder» y le motejaban de «ministro que sólo es conservador por conservar su empleo» y de «adulador de Montpensier» para "confundirse con la grey conservadora» ${ }^{40}$.

Más allá de las desencaminadas acusaciones en lo relativo a las preferencias sagastinas para alcanzar el trono, pudiera parecer, a los ojos de la prensa republicana, que el ministro riojano hubiera encarnado personal y unilateralmente la política represiva del gabinete. Sin embargo, una mirada más atenta permite comprobar que su línea de actuación también era entonces compartida por otros ministros presumiblemente más indulgentes con la causa republicana. Así, el nuevo titular de Gracia y Justicia, Ruiz Zorrilla, enviaba en noviembre de ese año instrucciones al Ministerio Fiscal para la oportuna investigación y reparación de los delitos cometidos. En ellas no dudaba en recalcar que el ejercicio de los derechos individuales y las libertades de reunión, asociación e imprenta sancionadas por la Constitución «habrán de respetar todas las instituciones, todos los poderes constitucionales [...], como la Monarquía; [...], las Cortes; [...] así como el poder judicial». Lo que no era compatible, a juicio del político burguense, con

«la exposición violenta que tienda directamente a traducir las ideas en hechos por medio de la fuerza; la que se hace no para propagar una doctrina, sino para atacar por la violencia las instituciones consagradas por las leyes; la que, en fin, no se dirige a la razón, sino a las pasiones brutales e inconscientes»,

\section{por lo que advertía en tono amenazante que}

«entre la defensa de la forma monárquica o la republicana de gobierno y el ataque a la establecida por las Cortes en la Constitución que nos rige, se halla el Código Penal con la severidad de sus preceptos ${ }^{41}$.

39 El Sol de la República, 5 y 16 de septiembre de 1869, y 8 de febrero de 1870.

40 El Sol de la República, 16 de febrero, 16 y 28 de abril de 1870.

41 Instrucciones al Ministerio Fiscal, 24 de noviembre de 1869, AHN, Fondos Contemporáneos, serie A, legajo 44/2, expediente n. ${ }^{\circ} 17$. 
El propio Sagasta salía al paso de las acusaciones vertidas desde los bancos de la oposición republicana y justificaba su celo represor:

«Si el Sr. Zorrilla desempeñara la cartera de Gobernación y yo la de Fomento, él sería reaccionario y yo sería liberal. [...] Mientras ha sido sólo el Ministro de la Gobernación quien se os ha puesto en vuestro camino, $[\ldots]$ todos los ministros eran muy liberales, menos el de Gobernación; pero tienen que intervenir los demás Ministros, tiene que intervenir el Sr. Zorrilla, y entonces es tan liberal Zorrilla como Sagasta: mirad su circular y ved la diferencia que hay entre ella y la del Ministro de Gobernación»42.

Lo que resultaba innegable, más allá de los personalismos que asomaban en el ámbito ministerial y en la propia cúspide del progresismo histórico, era la inviable recuperación de la amalgama revolucionaria con los republicanos.

\section{LAS DOS ORILLAS DE LA REVOLUCIÓN Y, AL FIN..., LA MONARQUÍA}

$Y$ es que a esas alturas, la desconfianza y la beligerancia entre progresistas y republicanos había alcanzado un punto de no retorno. Prim, Sagasta y los progresistas siguieron empeñados en la búsqueda de un rey para el trono español, convencidos como estaban de que la forma monárquica resultaba indispensable para la estabilidad del país. Precisamente, sería el combatido ministro de Gobernación el que asumiría, por encargo directo de Prim, la tarea de «coronar la Revolución» ${ }^{43}$ al pasar a la cartera de Estado en enero de 1870. Aquella tarea, que comportó no pocas dificultades y tensiones internas y externas, pareció encontrar premio al aceptar Amadeo de Saboya finalmente la corona que se le había ofrecido reiteradamente. La proclamación del candidato tras votación en Cortes, que suponía su legitimación democrática como no se ha vuelto a producir en la trayectoria monárquica posterior, no fue así interpretada en ciertos sectores de la política española. Para los republicanos, aquella era una fecha «fatídica en la historia política del pueblo español, que le hará recordar las causas de sus desdichas y de sus dolores, de su ignorancia y de su miseria» y representaba «la marca de la restauración de su esclavitud intelectual, moral y material, que en vano intentará borrar de su frente ${ }^{44}$.

Las desagradables experiencias ya constatadas volvieron a sobrevolar el ambiente político. La anhelada llegada del nuevo monarca coincidió con la conmoción provocada por el atentado sufrido por el Presidente del Consejo, el general Prim, con fatal desenlace, del que nunca se vieron del todo exculpados ciertos sectores del republicanismo más radical. El magnicidio no sólo acabaría

42 DSC, Congreso, Cortes Constituyentes de 1869, sesión del 18 de diciembre de 1869, p. 4824.

43 La expresión es de PASCUAL SASTRE, I.: La Italia del Risorgimento y la España del Sexenio Democrático (1868-1874), Madrid, C.S.I.C., 2001, p. 133.

44 Córdova López, F.: Una fecha fatídica. ¡Diez y seis de noviembre de 1870!, Madrid, 1871, p. 25. 
provocando una fractura en el seno del progresismo, escindido en dos bloques (los constitucionales de Sagasta y los radicales de Ruiz Zorrilla), apenas año y medio después, sino que condicionó en demasía el desarrollo posterior de la "aventura» democrática del Sexenio. La incompatibilidad manifiesta entre buena parte del progresismo histórico (en concreto, los que optasen por seguir bajo la jefatura de Sagasta) y el republicanismo asomó durante el reinado de Amadeo, en el que se asistió a lo que se llamó «el deslinde de los campos», o sea, un partido que agrupó a los progresistas templados o «fronterizos» sagastinos y otro que apostó por entablar lazos con los demócratas y republicanos inspirado por el otrora «legalista» Ruiz Zorrilla. La línea adoptada por Sagasta quedó reflejada en su primer discurso parlamentario como Presidente del Consejo de Ministros, ya en enero de 1872, en el que aseguraba que

«El Ministerio es, por lo tanto, conservador de la Monarquía constitucional; es conservador de la dinastía de Saboya; es conservador de los derechos individuales, tales como están consignados en la Constitución del Estado; es, en fin, conservador de las instituciones fundamentales que la España se ha dado. Pero como [...] piensa llevar a la administración en sus diversos ramos y a la política en sus variadas esferas el espíritu progresivo que aquellas mismas instituciones consientan, el Ministerio en el sentido propio, en el sentido filosófico y hasta en el sentido histórico de la palabra, es progresista»45.

Sagasta apostaba una vez más por ensayar un difícil equilibrio entre la conservación del orden representado por el sistema monárquico constitucional y el ensayo de las libertades con aquel «espíritu progresivo» al que no quería renunciar ${ }^{46}$. La forma monárquica era, por tanto, irrenunciable. De ahí que la quiebra de la monarquía de Amadeo y la proclamación de la I República no encontraron en Sagasta y los «constitucionales» unos fieles valedores («no debía enarbolarse por el partido la bandera de la república ${ }^{47}$ ) aunque ésta fuese reconocida como forma de gobierno consumada. Sumidos durante los meses de vigencia republicana en una suerte de «retraimiento» eventual, el viraje conservador y centrípeto de Castelar en su «República de orden» estimuló sus expectativas.

En realidad, el nuevo golpe de fuerza encabezado por Serrano y escenificado con el desalojo del Congreso ordenado por el general Manuel Pavía por el que se ponía fin a la República Federal cumplía a medias sus propósitos. Aunque fue mantenida formalmente la fórmula republicana y se rechazó la solución restauradora propuesta ya entonces por Cánovas, el ejecutivo recayó en la figura de Se-

45 La última aseveración despertó risas en los bancos de la izquierda, DSC, Congreso, Legislatura de 1872, sesión del 22 de enero de 1872, p. 25.

${ }^{46}$ Los complejos equilibrios de la política sagastina están descritos con precisión en MILÁN GARCíA, J. R.: «Orden y progreso. Los límites del liberalismo sagastino», en SUÁREZ CORTINA, M.: Las máscaras de la libertad. El liberalismo español, 1800-1950, Madrid, ed. Marcial Pons / Fundación Práxedes Mateo Sagasta, 2003, pp. 229-264; un análisis más amplio de su trayectoria hasta la Restauración, en OlleRo VAlLÉs, J.L.: Sagasta. De conspirador..., op. cit.

47 La lberia, 1 de octubre de 1873. 
rrano, que inició un mandato autoritario sin ningún tipo de refrendo parlamentario que sólo cabe calificar de dictatorial ${ }^{48}$. En un desesperado intento de salvaguardar las esencias, ya casi evanescentes, de la Revolución, Sagasta volvió a ser llamado para hacerse cargo de la cartera de Estado, primero, y de Gobernación, después. El apremiante envite carlista del Norte y las inciertas campañas militares allí libradas condujeron consecutivamente a Serrano y Zavala a la supervisión personal de las operaciones, por lo que Sagasta no dudó en aceptar en septiembre la Presidencia del Consejo de Ministros ante las prolongadas ausencias de ambos. Aquellos meses de gobierno únicamente parecían orientados a la finalización de la guerra civil y el mantenimiento del orden público.

En efecto, aunque Sagasta trató de reorganizar el Partido Constitucional, aquel mandato ya nada tenía que ver con los proyectos y las realizaciones de los primeros gobiernos revolucionarios tras la Gloriosa. La bandera del progresismo histórico había quedado definitivamente arriada y, puestos a renunciar, Sagasta hasta llegó a disolver la sociedad empresarial que había sostenido la publicación de La Iberia, traspasándola a otros propietarios. El cúmulo de las sucesivas frustraciones y desengaños, personales y políticos, del Sexenio hacían mella en un acorralado Sagasta, que volvía a recibir ataques constantes desde la prensa radical, algunos de ellos encabezados por antiguos amigos y conmilitones.

En estas circunstancias, poca resistencia podía ofrecer el desgastado líder liberal a las maniobras preparatorias para la restauración monárquica en la persona del hijo de la destronada Isabel II, que eran convenientemente anunciadas durante las últimas semanas de 1874. Además, con ello se aseguraba, no sólo la posibilidad de «aprender de los fracasos» anteriores sino, además, una nueva oportunidad de consolidación monárquica constitucional y, así, «restablecer en nuestra patria el principio de autoridad y hacer efectivas nuestras doctrinas [...] si bien dentro de la forma de gobierno que encontrábamos establecida, a la que no debíamos hacer traición ${ }^{49}$. Tras la vorágine política que habían experimentado los liberales progresistas a lo largo del Sexenio, buena parte de ellos (los que seguían siendo leales a Sagasta) seguían amarrados a uno de los principios políticos que nunca habían abandonado: la monarquía, a pesar de la traumática experiencia de la última Borbón. En realidad, la restauración monárquica a través de su hijo Alfonso tal

48 Sobre este periodo contamos con el estudio de TORO MÉRIDA, J.: Poder político y conflictos sociales en la España de la Primera República: la República del general Serrano (tesis doctoral), Universidad Complutense, 1997; ver también del mismo autor «La República unitaria de 1874: el 'acto' del 3 de enero y sus consecuencias políticas», en SERRANo García, R.: España, 1868-1874: nuevos enfoques sobre el Sexenio Democrático, Valladolid, Junta de Castilla y León, 2002, pp. 93-110.

49 La cita procede de la Carta-circular del Sr. Sagasta a los Comités del Partido Constitucional, 2 de mayo de 1875, en la que éste explicaba la evolución del Partido desde aquella Junta Directiva, Archivo General de Palacio, cajón 25/N; para la adaptación y el encaje político de los constitucionales en la Restauración alfonsina, ver también MILÁN GARCíA, J. R.: «Los liberales en el reinado de Alfonso XII: el difícil arte de aprender de los fracasos», AYER, n. ${ }^{\circ}$ 52, 2003, pp. 91-116 y LARIO, A.: «Alfonso XII. EI rey que quiso ser constitucional», ibidem, pp. 15-38, y El Rey, piloto sin brújula. La Corona y el sistema político de la Restauración, Madrid, ed. Biblioteca Nueva, 1999. 
vez fuese a comienzos de 1875 el único referente en común con los conservadores canovistas y un primigenio punto de partida para futuras colaboraciones.

Por otro lado, parece claro que uno de los activos políticos que garantizaba el hombre que habría de aglutinar bajo su liderazgo las desorientadas huestes liberales en el futuro régimen era su incuestionable fe monárquica. En este punto, como en otros, difícilmente podría sostenerse la pretendida volatilidad doctrinal del que acabaría siendo tal vez el político más indispensable de la restauración borbónica. Lo que ha dado en llamarse "giro sagastino" (del agitador y conspirador al hombre de gobierno y estadista de orden) no fue en modo alguno aplicable a la delicada cuestión de la forma de gobierno, dadas las firmes convicciones monárquicas que mostró a lo largo de su trayectoria. Lástima que no siempre encontrase en Palacio similares convicciones liberales. 